\title{
Violência doméstica e sexual no âmbito da Estratégia de Saúde da Família: atuação profissional e barreiras para o enfrentamento
}

I ${ }^{1}$ Roberta Taynan Souza Porto, ${ }^{2}$ José Patrício Bispo Júnior,

${ }^{3}$ Elvira Caires de Lima I

Resumo: A violência doméstica e sexual é um fenômeno complexo, com múltiplas determinaçôes. A abordagem do problema exige outros saberes além dos clínicos e biológicos. O estudo objetivou analisar as percepções dos profissionais da saúde da família a respeito do enfrentamento da violência doméstica e sexual. Realizou-se pesquisa qualitativa com 18 profissionais de sete equipes de saúde em Vitória da Conquista-BA. Para a análise, utilizou-se o método de codificação e categorização temática.

Os resultados evidenciaram duas categorias centrais: atuação profissional no atendimento aos casos; e barreiras e dificuldades para o enfrentamento da violência. Os profissionais demonstraram dificuldades em identificar os casos e sua atuação está centrada na abordagem sintomatológica. As principais dificuldades percebidas referem-se ao medo e à insegurança, à sobrecarga de atribuições e à formação inadequada. Considera-se a necessidade de articulação intersetorial e o desenvolvimento de políticas de educação permanente.

Palavras-chave: violência doméstica; violência sexual; atenção primária à saúde; profissional de saúde; saúde da família. 
A inclusão da violência na pauta do setor saúde ocorreu de maneira lenta e fragmentada. Vista inicialmente apenas como problema do âmbito da justiça e da segurança, a violência passou a ser considerada como questão de saúde motivada pela demanda de atendimento pontual e específico das lesões, traumas e mortes. Na perspectiva da saúde pública, dentre os motivos que levaram ao reconhecimento do problema, destacam-se o impacto sobre o perfil demográfico e epidemiológico da população e as várias implicações para os sistemas de saúde, sobretudo as decorrentes da grande necessidade de assistência, emergência e reabilitação das vítimas (MINAYO, 2007).

Por afetar a saúde individual e coletiva das populações, a problemática da violência ganhou destaque mundial. Além de produzir consequências à vítima, ao agressor e aos familiares, a violência também afeta o desenvolvimento econômico e social, desencadeando consequências para toda a sociedade. Seu enfrentamento exige a formulação de novas políticas públicas intersetoriais e a reorganização da estrutura social e da assistência à saúde (REICHENHEIM et al., 2011).

O Relatório da Organização Mundial da Saúde (OMS) destaca a responsabilidade dos profissionais da saúde, cientistas e diversos setores sociais nas ações de identificação da violência silenciosa e nos processos de intervenção, além de apontar a mesma como fenômeno previsível e passível de prevenção. Recomenda ainda a adoção de estratégias interdisciplinares, intersetoriais e multiprofissionais para enfrentamento do problema (OMS, 2002). Dentre as diferentes manifestações das violências, encontra-se a violência doméstica e sexual, fenômeno muito frequente em todos os países e com capacidade de causar direta ou indiretamente consequências graves e duradouras em todos os segmentos sociais (REICHENHEIM et al., 2011).

A violência doméstica é toda e qualquer ação ou omissão que acarreta prejuízos na liberdade e no desenvolvimento dos envolvidos, sejam eles membros da mesma família ou agregados e visitantes esporádicos. Tais atos podem ser cometidos dentro ou fora do lar e consistem, na grande maioria dos casos, em agressōes físicas, psicológicas, sexual e negligência (SALIBA et al., 2007; DAY et al., 2003). Suas vítimas são mulheres, crianças, idosos e portadores de deficiências, pessoas essas que se encontram em situação de vulnerabilidade ou desvantagem 
de força física. Não se caracterizam como violência doméstica as brigas de rua ou atos violentos entre homens de idade adulta.

A violência sexual é definida como o ato sexual realizado sem o desejo de uma das partes ou comercialização da sexualidade e utilização da sexualidade de um indivíduo através da intimidação, ameaça e uso da força (DAHLBERG; KRUG, 2007). A Lei no 11.340/2006, conhecida como Lei Maria da Penha, conceitua a violência sexual como qualquer ato que constranja o indivíduo a presenciar, manter ou participar de uma prática sexual não desejada. Ou ainda o anulamento dos direitos sexuais e reprodutivos, seja por meio da proibição do uso de métodos contraceptivos, da prostituição ou da indução ao aborto (BRASIL, 2006). Esse tipo de violência se configura como uma violação dos direitos sexuais e reprodutivos e como uma das formas mais hediondas de violência (OLIVEIRA, 2007).

O Ministério da Saúde estabelece distinções sobre as tipologias de violência doméstica e sexual, referindo-se às modalidades ou expressão dos atos violentos, que podem ocorrer de maneira isolada ou concomitante. Neste sentido, a violência doméstica pode ser perpetrada pelas seguintes formas: violência física; violência psicológica; violência sexual; tráfico de pessoas; violência financeira e econômica; negligência e abandono; trabalho infantil e intervenção legal (BRASIL, 2009a).

Diversos autores reconhecem os serviços de saúde como imprescindíveis para o enfrentamento e a abordagem da violência doméstica (WANDERBROOCKE; MORÉ, 2012; SCHRAIBER; D’OLIVEIRA; COUTO, 2009). No entanto, estudos sobre a temática apontam as fragilidades e limitações do setor tanto para o atendimento às vítimas como para a prevenção de novos casos. Segundo Leal, Lopes e Gaspar (2011), a assistência à saúde das vítimas de violência tem baixo poder resolutivo, o que faz com que esses indivíduos, principalmente mulheres, utilizem com maior frequência as unidades, acarretando maiores custos ao sistema de saúde em decorrência do seu uso repetitivo e ineficaz.

$\mathrm{Na}$ abordagem do setor saúde, ainda predomina uma lógica de atendimento sintomatológico voltada para o tratamento de lesões físicas e das sequelas dos atos violentos. Alguns fatores são referidos pela literatura como relacionados às limitaçôes da atuação do setor. Ainda se faz presente nas sociedades contemporâneas a reprodução de padrôes culturais em que se aceitam a punição física ou outros tipos de violência como prática educativa (LOBATO; MORAES; NASCIMENTO, 2012). Também a existência de problemas estruturais e 
conjunturais do setor saúde acaba por afetar a atuação dos profissionais. Neste sentido, destacam-se: a sobrecarga dos profissionais de saúde; a inadequação dos espaços físicos das unidades para atendimento às vítimas; e o insulamento do setor frente às dificuldades de articulação para abordagem intersetorial do problema (DE FERRANTE; SANTOS; FERREIRA, 2009). Além do mais, questôes relacionadas ao medo de represálias, falta de tempo e o sentimento de impotência dos profissionais contribuem para a atuação superficial, fragmentada e pouco resolutiva (WANDERBROOCKE; MORÉ, 2012).

Frente a este cenário, a Atenção Primária à Saúde (APS) destaca-se como nível de atenção privilegiado para o enfrentamento da violência doméstica e sexual. A reorganização do modelo assistencial, por meio da Estratégia de Saúde da Família, possibilita a longitudinalidade do cuidado e o desenvolvimento de vínculos entre usuários e profissionais, o que potencializa a identificação e a intervenção sobre as diversas formas de violência. Outra questão relevante é a ênfase dada às ações de promoção à saúde e de prevenção de agravos, que buscam não apenas atuar no problema já instalado, mas, sobretudo, evitá-lo (D’OLIVEIRA et al., 2009).

Assim, os profissionais da saúde da família apresentam grande potencialidade para a detecção, abordagem e acompanhamento qualificado das vítimas. Esses profissionais lidam cotidianamente com situaçôes de violência doméstica e sexual e vivenciam na prática as dificuldades inerentes ao processo de assistência e acompanhamento dos casos (ANDRADE et al., 2011).

Ao considerar a relevância da APS e as responsabilidades da Equipe de Saúde da Família (ESF), este estudo teve como objetivo analisar as percepções dos profissionais da saúde da família a respeito do enfrentamento da violência doméstica e sexual.

\section{Tratamento metodológico}

Trata-se de um estudo com abordagem qualitativa do tipo descritivo exploratório. Segundo Minayo (2010), o método qualitativo é o que melhor propicia uma apreensão das relações entre o indivíduo e a sociedade, entre as ideias e a base material, entre a realidade e as correntes que enfatizam o sujeito histórico e a determinação social dos fenômenos. $\mathrm{O}$ método qualitativo tem como base o estudo das relações, percepções, crenças e opiniōes de diferentes indivíduos acerca de determinado contexto (FLICK, 2009). Assim, diante da complexidade do tema 
da violência e da subjetividade inerente à atuação dos profissionais de saúde na abordagem do problema, é que se optou pelo método de investigação qualitativa.

O estudo foi realizado na cidade de Vitória da Conquista, localizada na região sudoeste da Bahia, com população de 306.866 habitantes (IBGE, 2011). Segundo dados do Ministério da Saúde, no ano de 2012 o município possuía 38 ESFs, com cobertura populacional de $41,16 \%$ da saúde da família (BRASIL, 2013).

A coleta de dados foi realizada por meio de entrevista semiestruturada guiada por roteiro com questôes abertas. Como critérios de inclusão dos sujeitos da pesquisa, foram definidos os seguintes itens: profissionais de nível superior com atuação na ESF que se disponibilizassem em participar da pesquisa de forma livre e informada e que trabalhassem há mais de um ano na unidade de saúde onde estavam lotados. A adoção deste último critério objetivou excluir profissionais com diminuto vínculo com a comunidade e, portanto, com menor possibilidade de atendimento às vítimas de violência.

Foram entrevistados 18 profissionais pertencentes a sete diferentes equipes de saúde. No que se refere à categoria profissional, contemplaram-se sete enfermeiros, seis médicos e cinco dentistas. As entrevistas foram gravadas em aparelho de áudio digital e transcritas na íntegra pelo próprio entrevistador. A realização das entrevistas ocorreu entre os meses de fevereiro e abril de 2012.

Para a análise, utilizou-se o método de codificação e categorização temática proposto por Gibbs (2009). De acordo com o autor, a codificação/categorização é uma forma de indexar o texto para estabelecer uma estrutura de ideias temáticas em relação ao conteúdo estudado. Neste sentido, o processo de codificação envolve a identificação e o registro de uma ou mais passagens do texto que, em algum sentido, exemplificam a mesma ideia teórica e/ou descritiva. Desta forma, a todo recorte de texto que se refere a um conteúdo semelhante ou exemplifica algo de igual sentido é atribuído o mesmo código.

Após a leitura exaustiva e reflexiva do texto, foram definidos e descritos os códigos que expressavam as principais ideias analíticas dos discursos. $\mathrm{O}$ processo de codificação/categorização foi realizado em duas etapas distintas e complementares. Na primeira, denominada de codificação aberta, buscou-se identificar partes do texto e estabelecer quais códigos eles representavam de forma teórica e analítica. $\mathrm{Na}$ segunda etapa, codificação axial, analisaram-se os recortes dos discursos aos quais foram atribuídos os mesmos códigos, buscando- 
se identificar possíveis relações entre os vários discursos. Assim, num processo de refinamento, desenvolvimento e interconexão, foram delimitadas as categorias e subcategorias temáticas do estudo (GIBBS, 2009).

Duas categorias emergiram como temas centrais da investigação: (1) Atuação profissional no atendimento aos casos de violência e (2) Barreiras e dificuldades para o enfrentamento da violência doméstica e sexual. Cada uma dessas categorias é composta por suas respectivas subcategorias, conforme apresentado na tabela 1. Importante destacar que essas categorias e subcategorias fazem parte da rede interpretativa de sentidos e significados dos entrevistados, estando, portanto, entrelaçadas e interconectadas entre si.

Tabela 1. Categorias e subcategorias do estudo sobre percepção da violência doméstica e sexual pelos profissionais de saúde

\begin{tabular}{lcc}
\hline Categorias & Atuação profissional & Barreiras e dificuldades \\
\hline Subcategorias & Identificação dos casos & Medo e Insegurança \\
& Atitudes dos & Sobrecarga de atividades \\
& profissionais frente aos & Formação e despreparo dos profissionais \\
casos & Dependência financeira e emocional da vítima \\
\hline
\end{tabular}

O estudo obedeceu às diretrizes da Resolução no 196/96 do Conselho Nacional de Saúde, quanto aos aspectos éticos e científicos das pesquisas com seres humanos. Foi aprovado pela Comissão de Pesquisa da Secretaria Municipal de Saúde de Vitória da Conquista e concedida autorização para a coleta de dados. Também foi aprovado pelo Comitê de Ética em Pesquisa (CEP) da Universidade Estadual do Sudoeste da Bahia (UESB), conforme parecer do protocolo n $195 / 2011$.

\section{Resultados e discussão}

\section{Atuação profissional no atendimento aos casos de violência}

Os profissionais entrevistados reconheceram a complexidade da violência doméstica e sexual e identificaram a Saúde da Família como estratégia privilegiada para o enfrentamento do problema, devido à proximidade e ao vínculo com as comunidades, além de propiciar a possibilidade de continuidade e de acompanhamento das ações iniciadas. 
Aqui na unidade de saúde facilita a identificação das vítimas. Você cria um vínculo

muito grande, a pessoa se abre, né? [...] O local eu acho ideal pra você estar identificando esses casos. Toda a equipe. (Entrevista 18)

A identificação dos casos de violência é a fase primordial da atuação profissional. No caso das ESF, esse processo apresenta potenciais vantagens por conta da facilidade de acesso e do vínculo com as comunidades. Todavia, os resultados do estudo revelaram dificuldades para a identificação das vítimas e que esta não é uma prática cotidiana por parte dos profissionais. Esses afirmaram nunca ter identificado um caso de violência doméstica.

Não, sinceramente não, nunca suspeitei. [...] Dá para a gente mais ou menos suspeitar. Mas, sinceramente eu nunca. (Entrevista 14).

A dificuldade em identificar as vítimas de violência relaciona-se ao fato que a demanda explícita por atendimento em decorrência desses abusos é considerada baixa, mesmo com a presença deste problema no cotidiano dos usuários. De maneira geral, a busca de atendimento é motivada pelos sintomas decorrentes das agressões, e a assistência oferecida nos serviços de saúde acaba por se restringir ao tratamento de lesões e ferimentos.

Geralmente as pessoas não vêm por causa da violência, geralmente elas vêm por outro motivo. Uma dor de cabeça muito forte, uma pressão, sensação de batimentos cardíacos acelerados, essas coisas. (Entrevista 13)

Diante da não manifestação explícita das vítimas de violência, os profissionais de saúde devem estar sensibilizados quanto ao problema e atentos aos sinais, sintomas e indicativos das agressōes para que se consiga identificar os casos. Esta situação da baixa manifestação explícita para o atendimento das situações de violência doméstica e sexual pode indicar duas situações. Uma motivada pelo medo do agressor, vergonha ou naturalização da violência. E outra pelo não reconhecimento do setor saúde, especialmente da Atenção Primária à Saúde, como serviço adequado para a busca de atenção e apoio.

Observa-se, pois, que a violência doméstica é marcada por invisibilidade, silêncio e negação. A invisibilidade da violência tem sido discutida em muitos estudos (BORSOI; BRANDÃO; CAVALCANTI, 2009; SANTOS; VIEIRA, 2011; SANTOS et al., 2011) e pode estar relacionada à restrita atuação do setor saúde, que, muitas vezes, limita-se a agir na perspectiva queixa/conduta. Diante disso, emerge a necessidade de ampliar a visão dos profissionais sobre os 
problemas de saúde da população e estimular a execução da clínica ampliada. Torna-se necessário utilizar uma abordagem integral nas consultas e fazer uso de perguntas diretas sobre as causas dos problemas e sobre situações específicas de violência (COOPER; SELWWOD; LIVINGSTON, 2008).

A invisibilidade da violência também está relacionada à aceitação de determinadas situações violentas e também à tolerância social do problema, o que conduz a um processo de naturalização da violência (SANTOS; VIEIRA, 2011).

A banalização da violência doméstica pelas vítimas e familiares foi referida pelos profissionais entrevistados. A percepção dos profissionais é que, muitas vezes, as agressões são negligenciadas em decorrência das vítimas considerarem os atos violentos como normais e naturais. Outra faceta apresentada relaciona-se ao fato de as vítimas nem perceberem os atos violentos; nestes casos, a violência é tão fortemente introjetada no convívio e na cultura local que se torna imperceptível para as vítimas, famílias e comunidades. Os achados do estudo demonstraram que a tolerância social da violência é justificada pela intenção de educar, impor limites, demonstrar afeto ou pelo estado alcoólico e estresse do agressor.

Apesar das situações de violência doméstica terem sido mencionadas pelos profissionais como aceita e tolerada pelos usuários, os resultados evidenciaram que os próprios profissionais também naturalizam as açôes de violência vivenciada nas comunidades. Diante disso, a naturalização da violência doméstica - tanto pelas comunidades como pelos profissionais - representa um entrave importante ao enfrentamento dos casos.

Embora parte dos profissionais tenha apontado dificuldades em identificar os casos e demonstrado não se sensibilizar com a problemática, outro grupo relatou maior habilidade em sua prática profissional. Alguns relataram a utilização de diversos meios, a exemplo de denúncia anônima, avaliação clínica e relato dos agentes comunitários de saúde (ACS) para a identificação de situações de violência.

E também na anamnese ou na historia do paciente. Você sente quando o paciente ta vacilando, tá receoso. Aí você já começa suspeitar que tem alguma coisa ali escondido que ele não esta querendo revelar. [...] A gente pergunta, vai perguntando devagarzinho de maneira que o paciente, ele vai adquirindo confiança e aos pouco vai se soltando mais, né? (Entrevista 06).

O trabalho dos ACS foi mencionado pelos entrevistados como de fundamental importância para a abordagem e o enfretamento do problema. Por atuarem diretamente com as comunidades, pertencerem à mesma realidade e manter uma 
relação próxima com a população local, estes são percebidos pelos entrevistados como profissionais de referência quando o assunto é a identificação dos casos.

Os ACS atuam juntamente com a equipe. E pra gente identificar juntos aos agentes é mais fácil. Porque o agente, ele mora na área, né? Ele frequenta diretamente a casa, né? [...] Geralmente ele já sinaliza a casa, o caso de agressão pra mim. (Entrevista 02).

Importante destacar que a atuação dos agentes comunitários sobre a temática da violência é permeada de conflitos e incertezas. Os ACS, por conhecerem a realidade social do território e conviver nas comunidades, têm maior possibilidade de detectar e intervir sobre os aspectos relativos às condições de vida da população (GOMES et al., 2010). Por outro lado, esses profissionais têm dificuldade para enfrentar a violência em sua prática cotidiana, seja por não perceberem determinados episódios como situações de violência ou por receio de sinalizar para a equipe os casos identificados.

Não se observou uma postura uniforme dos profissionais em relação a sensibilidade e comprometimento com os casos. Alguns demonstraram comoção e se abalaram com situações vivenciadas por algumas das vítimas, como foi o caso de uma entrevistada que não conteve as lágrimas ao comentar uma situação de violência cometida pelo pai a uma criança. Outros preferem se manter distantes e consideram que quanto menos se envolverem, melhor, como exemplificado pela fala: "A gente liga o automático e segue" (Entrevista 08).

Os profissionais referiram a escuta e o acolhimento como ações iniciais na atenção às vítimas. No entanto, observa-se que a prática do acolhimento desenvolvida, em muitas situaçôes, acaba por se restringir a receber esses indivíduos e a ouvir suas queixas.

Eu direciono através de uma conversa. De escutar a paciente, né? Tentar escutar o que ela ta falando, porque às vezes a gente nem escuta o que ela ta falando. Tentar escutar, colher aquela conversa dela. [...] É só mesmo uma questão de conversar, de orientar, de tentar levantar a autoestima dessa mulher, né? Eu lido dessa forma, desse jeito. Tentar conversar, escutar, levantar a autoestima dela. (Entrevista 07)

Apesar de a escuta permitir à vítima expressar as situações dos conflitos vivenciados e possibilitar conforto pela expressão da fala, o ato de ouvir, por si só, não se constitui na realização do acolhimento. $\mathrm{O}$ acolhimento é uma das diretrizes da Política Nacional de Humanização da Atenção e Gestão do Sistema Único de Saúde (SUS) e não se limita a recepção, escuta e inclusão dos usuários nos serviços de saúde. Compreende, sobretudo, atendimento com responsabilização e resolutividade dos casos, garantindo, quando necessário, a 
continuidade da assistência em outros serviços por meio do encaminhamento qualificado (BRASIL, 2009b).

Visto como meio para se estabelecer vínculos de confiança e empatia nas relaçōes entre serviços de saúde, profissionais e usuários, o acolhimento deve ser assegurado como prática que garanta uma assistência humanizada e resolutiva. É compreendido como um instrumento com potencialidade para fortalecer e qualificar as ações de saúde. Tal ferramenta visa transformar a atuação dos profissionais e fortalecer a atenção primária, com contribuição decisiva para a consolidação dos princípios do SUS (SANTOS; SANTOS, 2011).

Por sua vez, emergiram também relatos de abordagem ampliada e de realização de encaminhamentos. Alguns profissionais referiram orientar às vítimas acerca do fenômeno da violência vivenciada, encorajar a busca de alternativas para o enfrentamento do problema e incentivar a procura por serviços especializados disponibilizados pela gestão municipal.

A gente lida orientando. E orientando pra ela que ela teve... que ela sofreu uma violência, né? E também orienta também a questão assim, de ta buscando o serviço para esse tipo de atendimento. (Entrevista 02)

Os serviços especializados mencionados pelos profissionais são os que compõem a rede de apoio e atenção às vítimas de violência doméstica e sexual existente no município. Esta rede é constituída por serviços da área da saúde, setores jurídicos, policiais e de assistência social, a exemplo do Centro de Referência da Mulher, Delegacia Especializada no Atendimento à Mulher, Conselho do Idoso e Conselho Tutelar.

Apesar de os profissionais afirmarem conhecer a existência de determinados serviços que atendem às vítimas de violência, relataram não conhecer a existência de uma rede intersetorial para atenção às vítimas. Observa-se que a atitude dos profissionais em orientar a busca por serviços fora da área da saúde ocorre de maneira informal, descontextualizada e não constitui rotina institucional a partir da articulação do setor saúde com os outros segmentos.

Conhecer os diversos serviços que compõem a rede de atenção e prevenção da violência é um passo importante para a articulação intersetorial. No entanto, é preciso modificar o processo de trabalho dos profissionais, pois se evidenciaram dificuldades destes em trabalhar, pensar e agir em rede. As atitudes profissionais ainda estão demarcadas por trabalhos isolados e desarticulados, o que evidencia 
a dificuldade de se operacionalizar a abordagem interdisciplinar tão necessária ao enfrentamento da violência.

O desconhecimento, por parte dos profissionais, da existência de redes de atenção às vítimas de violência foi também observado por Moreira et al. (2008), que destacam a possibilidade de a desinformação acarretar prejuízos no apoio multiprofissional e intersetorial às vítimas. Essa posição é corroborada por Santos e Vieira (2011), ao afirmarem que o desconhecimento das redes de serviços existentes constitui fator de grande limitação para a abordagem integral dos problemas de saúde.

O modelo de atuação em rede é o mais indicado para a abordagem da violência, uma vez que as relações ocorrem de forma horizontalizada e qualquer um dos serviços pode atuar como porta de entrada para a atenção às vítimas. Por meio de ações articuladas, intersetoriais e multiprofissionais, o trabalho das redes fornece a vítimas e familiares suporte jurídico, psicossocial e de saúde, o que amplia a possibilidade de solução do problema (D'OLIVEIRA et al., 2009).

Evidenciou-se também no discurso dos profissionais que os encaminhamentos seriam uma forma de se livrar do problema, por não saberem lidar ou não quererem se envolver na situação.

A gente encaminha. Eu geralmente encaminho, não tenho muito o que fazer, eu aqui, né? [...] Então mando, encaminhado pro hospital pra fazer avaliação física, né? Encaminho pro hospital de referência, a gente encaminha pro CAPS. (Entrevista 04).

A gente passa essa demanda pra esses conselhos e só. É o que eu faço, é o que eu tenho feito. (Entrevista 05).

Diante da perspectiva da integralidade do cuidado, torna-se fundamental que os encaminhamentos se façam de maneira articulada com o setor de destino e que o vínculo do usuário seja mantido em ambos os serviços, de maneira que se fortaleçam os pontos de encontro e a articulação que devem existir na rede.

Borsoi, Brandão e Cavalcanti (2009) observam que a identificação de um caso de violência doméstica deve ser apenas o início de um processo que busque apoiar as vítimas na superação do problema. Nesse contexto, advertem que os encaminhamentos não devem ser numa referência para fora do serviço e posterior perda de controle sobre os desdobramentos de sua ação, mas uma estratégia destinada a envolver diversos segmentos na articulação para a resolução do problema. 
Outra estratégia mencionada por parte dos entrevistados como forma de enfrentar o problema da violência doméstica e sexual foi tentar incluir os agressores no atendimento oferecido nas unidades de saúde. Os profissionais revelaram que, de forma discreta, atraem os agressores para a unidade de saúde, utilizando como recurso a oportunidade de uma consulta. Empregam uma abordagem diferenciada para que se consiga identificar fatores desencadeantes dos atos violentos, como o alcoolismo e o ciúme, e oferecem os encaminhamentos e suportes necessários ao agressor.

Mas tem que ir atrás do agressor. Senão vai ficar como? Só cuidando de vítimas? Aí esse agressor não vai deixar de agredir nunca, né não? (Entrevista 06).

Eu peço pra vim ela e o marido. E tem vindo ela e o esposo. Aí eu converso. [...] Vou suave, pelas bordas. Não chego na questão: "ah, você bateu." Não, não tenho como fazer isso. Se eu fizer isso o cara vai fugir de mim e eu quero trazer ele pra mim. Não quero que ele fuja de mim, né? Ele vem, a gente bate um papo, converso com ele falando sobre a bebida alcoólica, eu já falo mais de uma forma descontraída sobre a cachaça, sobre a bebida, em si. Falo de uma forma descontraída pra manter ele aqui, perto de nós, aqui. Pra tentar resgatar esse indivíduo. (Entrevista 04).

Ainda há uma lacuna de conhecimentos em relação à abordagem e tratamento do agressor (GONTIJO et al., 2010). Conforme destacam Lima e Büchele (2010), essa questão não se resume à escassez de publicações, mas sobretudo à diminuta presença de serviços que prestam atendimento e acompanhamento aos homens autores da violência. A abordagem do agressor para além da repressão e punição não se configura como política pública no Brasil e países latino-americanos. Assim, o envolvimento dos homens na prevenção, atenção e enfrentamento à violência doméstica permanece incipiente, o que pode denotar limitaçôes na abordagem do problema. Profissionais que prestam atenção aos homens autores de violência em um serviço de Santa Catarina demonstraram dificuldade de desenvolvimento da práxis, em decorrência da ausência de referencial teórico e treinamento empírico para a abordagem (LIMA; BÜCHELE, 2010).

\section{Barreiras e dificuldades para o enfrentamento da violência doméstica e sexual}

Dentre as muitas barreiras e dificuldades percebidas, a insegurança e o medo foram as mais evidenciadas nos discursos. Os profissionais sentem-se expostos e vulneráveis ao lidarem com situações de violência. $\mathrm{O}$ temor às possíveis represálias e intimidações de agressores interfere no agir dos profissionais que, muitas vezes, 
não abordam a dimensão social do problema, restringindo-se a intervir sobre lesões

físicas. Os entrevistados evidenciaram mudanças em sua atuação profissional, em decorrência do medo e da preocupação com sua própria segurança.

A principal dificuldade é a insegurança, né? Porque você não tem uma segurança, uma confiança na atuação da polícia, na atuação da justiça, né? [...] É um bairro que é violento e tal. A gente fica muito preocupado em denunciar alguma coisa. A gente também corre riscos nesse bairro, porque a gente não sabe com quem a gente está lidando. As pessoas do bairro são envolvidas com o tráfico, outros crimes violentos acontecem no bairro. (Entrevista 09).

O sentimento de medo revelado conduz a atitudes de autoproteção dos profissionais, que por se sentirem inseguros em suas ações e desprotegidos pelos poderes públicos, preferem não se aprofundar na abordagem com as vítimas e não se envolver na resolução dos casos. Emergiram também sentimentos de raiva e de revolta diante das situações de violência doméstica e sexual. Alguns profissionais demonstraram ficar indignados com alguns relatos das vítimas, no entanto referiram impotência frente à complexidade do problema.

Os profissionais apontaram que a sobrecarga de ações e atividades da saúde da família constitui um dos principais fatores que limitam sua atuação.

A estratégia de saúde da família, ela é meio que sobrecarregada. Todas as ações da atenção básica, elas são despejadas no colo da saúde da família, entendeu? [...] Então tudo isso acaba meio que sobrecarregando. (Entrevista 05).

Para os entrevistados, a atenção dispensada aos usuários do serviço não ocorre de maneira adequada, sobretudo pela elevada quantidade de atribuições sob responsabilidade dos profissionais, pelo elevado número de famílias por equipe, pelo processo de avaliação de desempenho centrado na produtividade e pelo excesso de atividades gerenciais e burocráticas.

Nós somos poucos profissionais para uma população bem ampla. Você está entendendo? [...] Porque você colocar mais responsabilidade em cima dos profissionais do PSF, como já existe, você está sobrecarregando o profissional e no final das contas ele não vai fazer nada corretamente. (Entrevista16).

É porque assim, na verdade a gente é envolvido por uma coisa chamada produtividade. Muitas vezes você tem que produzir. [...] Muitas vezes, você passa batido por essas questōes. Então, é o dia a dia mesmo. Assim, velocidade com que as coisas acontecem, não dá tempo pra gente se envolver em questóes como essas. (Entrevista 08).

Segundo Moreira e colaboradores (2008), existe no âmbito das ESFs grande quantidade de atividades a serem desenvolvidas e um exíguo tempo de trabalho 
disponível para dar conta das atribuições. Tal equação desencadeia, com frequência, a realização de atendimentos rápidos, superficiais e direcionados para os sintomas apresentados, sem a devida preocupação sobre as causas ou determinações do problema.

O comprometimento da qualidade da atenção à saúde oferecida pela Estratégia de Saúde da Família também é apontado por diversos autores (ONOCKOCAMPOS et al., 2012; SERAPIONI; SILVA, 2011). Em estudo avaliativo da APS no estado do Ceará, Serapioni e Silva (2011) concluíram que a relação do número de pessoas por equipe necessita ser redimensionado, pois é um aspecto crítico para a má qualidade do serviço.

Além da relação número de usuários por equipe, importante também destacar a necessidade de promover a distribuição equitativa de responsabilidades dentro da Equipe de Saúde da Família, visto que, na dinâmica de trabalho da ESF, prevalece a concentração de responsabilidades sobre o profissional enfermeiro, principalmente no que se refere às atividades gerenciais. Outra dificuldade apresentada pelos profissionais é que estes não se percebem devidamente preparados para a abordagem e acompanhamento aos casos de violência, seja com as vítimas, com os agressores, com os familiares e com a própria comunidade.

Então assim, pra lidar mesmo com a violência em si eu não estou capacitada pra isso. O que eu lido é tentar orientar a paciente dentro da minha capacidade como enfermeira ou como pessoa mesmo. Porque às vezes nem é como profissional, é como pessoa. Agora pra lidar com isso, com a própria violência eu não tô capacitada pra isso não. (Entrevista 07).

Diante da complexidade do fenômeno da violência e suas múltiplas dimensões, os profissionais se consideram impotentes para o enfrentamento do problema e reconhecem que a abordagem clínico-biológica é insuficiente e limitada. Sentemse despreparados e com pouco conhecimento para contemplar os aspectos sociais e psicológicos que a atuação sobre as situações de violência exige.

O sentimento de despreparo por parte dos profissionais também foi encontrado no estudo de D'Oliveira e colaboradores (2009). Os autores identificaram que o despreparo dos profissionais conduz a uma atuação limitada, com redução dos problemas às manifestação biológicas. Tal abordagem inviabiliza o desenvolvimento da atenção integral e intersetorial a um problema que não é só médico, mas, sobretudo, sanitário e social. Os entrevistados revelaram se 
sentir despreparados tanto por limitações na formação acadêmica no período da graduação - centrada no paradigma clínico-biológico - quanto da ausência da educação permanente na prática dos serviços de saúde. A dificuldade dos profissionais em lidar com as situações de violência conduz ao improviso e à atuação com base nas vivências e na sensibilidade pessoal, comprometendo, assim, a qualidade da assistência prestada.

A realidade do município estudado guarda similaridade com os achados de Moreira et al. (2008), para os quais as estratégias de abordagem utilizadas pelos profissionais muitas vezes se limitam aos conselhos práticos e fórmulas genéricas, em decorrência do despreparo e falhas na formação acadêmica. Segundo Oliveira (2007), há necessidade não apenas de investir na capacitação e sensibilização dos profissionais, mas atuar de forma a romper com crenças, preconceitos e julgamentos, fatores que podem interferir no desenvolvimento da assistência qualificada às vítimas. As limitações dos profissionais para lidar com o problema $\mathrm{da}$ violência acentuam as dificuldades das vítimas em identificar as unidades de saúde como local de apoio e acompanhamento, porque a qualidade da assistência prestada e o vínculo estabelecido entre esta e o serviço irá estimular ou dificultar o rompimento do ciclo da violência (SANTOS; VIEIRA, 2011).

Assim, evidencia-se a necessidade de investimentos em educação permanente como estratégia de sensibilização e qualificação dos profissionais da ESF para o enfrentamento da violência doméstica e sexual. A educação permanente, a partir da prática reflexiva e da socialização/integração dos diversos saberes, contribui para melhorar o desempenho profissional, desenvolver novas competências e construir novos conhecimentos. Propõe-se a formar atores crítico-reflexivos que avaliam e modificam sua prática e estão em constante busca de novos saberes (BRASIL, 2009c).

No entanto, a educação permanente só se operacionaliza quando ocorre a mudança institucional das práticas de educação e formação profissional (BRASIL, 2009c). Para Santos e colaboradores (2011), o desenvolvimento de ações de Educação em Saúde fundamentadas nas tendências pedagógicas libertadoras tem demonstrado resultados importantes para a transformação da práxis. Nesse sentido, há necessidade de superar as ações de treinamentos esporádicos, que geram modificações localizadas, individuais e temporárias, com natural incapacidade de provocar transformaçôes profundas sobre o agir dos profissionais. 

também como dificuldade para abordagem ao problema da violência e para o rompimento do ciclo da violência. Tal situação se apresenta de forma acentuada quando se trata da violência perpetrada contra a mulher.

É que essas mulheres pra se libertar elas precisam de outra coisa. Porque não adianta. Tem o conselho da mulher, conselho disso, conselho daquilo, mas essa mulher vai lá denunciar e volta pro mesmo lugar. Se ela não tem uma estrutura ou um emprego que faça ela ter uma independência... Porque a mulher sempre volta pro mesmo lugar, porque depende daquele marido, né? Depende. Se não tiver uma estrutura pra que ela consiga se libertar, ela sempre volta pro mesmo lugar e não adianta nada. (Entrevista 07).

A vulnerabilidade social e econômica presente no cotidiano de grande contingente das mulheres brasileiras fortalece a dependência financeira com relação a seus companheiros. Esta condição favorece a incapacidade da mulher em romper a relação estabelecida com o agressor, o que torna a situação de violência passível de constante repetição.

A situação da dependência financeira e emocional da vítima da violência doméstica exige do profissional de saúde uma atuação abrangente que envolva os aspectos culturais e sociais do problema. Neste sentido, deve-se buscar a inserção das vítimas nos programas de proteção e apoio social, como forma de alcançar a autonomia emancipatória para o rompimento do ciclo de violência estabelecido.

\section{Considerações finais}

O tema da violência doméstica e sexual é de grande relevância para a Saúde Coletiva, especialmente por sua invisibilidade e natureza multifacetada, o que demanda maiores desafios aos profissionais e serviços de saúde. O presente estudo buscou contribuir para a compreensão do fenômeno e seu enfrentamento ao se debruçar sobre a realidade percebida por profissionais de saúde no interior do Nordeste do Brasil. Os resultados apontam uma realidade permeada por dificuldades e limitações, que suscitam a necessidade de aprimoramento das políticas públicas relacionados à violência.

Os sujeitos do estudo reconheceram a complexidade da violência doméstica e sexual e perceberam a relevância da ESF para o enfrentamento do problema. No entanto, evidenciaram inabilidade para a identificação das vítimas e despreparo para a abordagem e o acompanhamento dos casos. 
$\mathrm{O}$ medo e a insegurança, bem como a sobrecarga de atividades no âmbito da saúde da família, foram destacados entre as principais barreiras para uma atuação em direção à integralidade. Ainda em relação às dificuldades percebidas, o estudo desvelou que problemas sociais e culturais - a exemplo da dependência financeira e emocional das vítimas e a presença de valores que naturalizam a violência - interferem sobremaneira na atuação dos profissionais.

Este estudo evidenciou a importância de incluir o tema durante o período de formação acadêmica e implementar políticas de educação permanente para a sensibilização e transformação das práticas profissionais. Problemas estruturais da rede de serviços de saúde devem ser enfrentados por gestores locais e nacionais, com o propósito de possibilitar condições de trabalho compatíveis com os pressupostos da Estratégia de Saúde da Família. Também as questões referentes a banalização/naturalização da violência devem ser encaradas por meio de discussões abertas entre comunidades e serviços de saúde. Assim, vislumbra-se a perspectiva da não ocultação da realidade vivenciada e o desenvolvimento de reflexôes coletivas sobre os valores sociais estabelecidos e as consequências sobre a saúde das comunidades.

Importante destacar que o setor saúde, de maneira isolada, pouco impactará no enfrentamento da violência doméstica e sexual. Para o alcance de uma atenção digna e integral, é indispensável o fortalecimento da articulação intersetorial, com a integração de todos os segmentos sociais envolvidos e a atuação em rede. Nesse contexto, serviços e profissionais de saúde têm responsabilidade destacada, e além da abordagem clínica, devem compreender sua atuação como articuladores do cuidado e sujeitos corresponsáveis pela garantia da integralidade da atenção. ${ }^{1}$

\section{Referências}

ANDRADE et al. A visão dos profissionais de saúde em relação à violência doméstica contra crianças e adolescentes: um estudo qualitativo. Saúde e Sociedade. São Paulo, v. 20, n. 1, p. 147-55, 2011.

BORSOI, T.S.; BRANDÃO, E.R.; CAVALCANTI, M.L.T. Ações para o enfrentamento da violência contra a mulher em duas unidades de atenção primária à saúde no município do Rio de Janeiro. Interface: Comunicação, Saúde, Educação. Botucatu, v. 13, n. 28, p. 165-74, 2009. BRASIL. Ministério da Saúde. Sala de Apoio à Gestão Estratégica em Saúde (SAGE). Disponível em: <http://189.28.128.178/sage/>. Acesso em: 21 fev 2013. 

Humanização da Atenção e Gestão do SUS. Acolhimento e classificação de risco nos serviços de urgência. Brasília: Ministério da Saúde, 2009b.

. Ministério da Saúde. Secretaria de Gestão do Trabalho e da Educação na Saúde. Política Nacional de Educação Permanente em Saúde. Brasília: Ministério da Saúde, 2009c.

Ministério da Saúde. Secretaria de Vigilância em Saúde. Instrutivo de preenchimento da ficha de investigação/notificação de violência doméstica, sexual e outras violências. Brasília: Ministério da Saúde, 2009a.

Presidência da República. Lei no 11.340, de 7 de agosto de 2006. Cria mecanismos para coibir a violência doméstica e familiar contra a mulher e dá outras providências. Diário Oficial da Uniāo, 08 de agosto de 2006.

COOPER, C.; SELWWOD, A.; LIVINGSTON, G. The prevalence of elder abuse and neglect: a systematic review. Age Ageing, v.37, p. 151-160, 2008.

D'OLIVEIRA, A.F.P.L. et al. Atenção integral à saúde de mulheres em situação de violência de gênero: uma alternativa para a atenção primária em saúde. Ciência \& Saúde Coletiva, Rio de Janeiro, v. 14, n. 4, p. 1037-50, 2009.

DAHLBERG, L.L.; KRUG, E.G. Violência: um problema global de saúde pública. Ciência \& Saúde Coletiva, Rio de Janeiro, v. 11, supl. 1, p.1.163-78, 2007.

DAY, V.P. et al. Violência doméstica e suas diferentes manifestaçóes. Revista de Psiquiatria do Rio Grande do Sul, Porto Alegre, v. 25, supl. 1, p. 9-21, 2003.

DE FERRANTE, F.G.; SANTOS, M.A.; VIEIRA, E.M. Violência contra a mulher: percepção dos médicos das unidades básicas de saúde da cidade de Ribeirão Preto, São Paulo. Interface: Comunicação, Saúde, Educação. Botucatu, v. 13, n. 31, p. 287-99, 2009.

FLICK, U. Desenho na Pesquisa Qualitativa. Porto Alegre: Artmed, 2009.

GIBBS, G. Análise de Dados Qualitativos. Porto Alegre: Artmed, 2009.

GOMES, K.O. et al. O Agente Comunitário de Saúde e a consolidação do Sistema Único de Saúde: reflexões contemporâneas. Physis: Revista de Saúde Coletiva. Rio de Janeiro, v. 20, n. 4, p. 1.143-64, 2010.

GONTIJO, D.T. et al. Violência e Saúde: uma análise da produção científica publicada em periódicos nacionais entre 2003 e 2007. Physis: Revista de Saúde Coletiva. Rio de Janeiro, v. 20, n. 3, p. 1.017-54, 2010.

INSTITUTO BRASILEIRO DE GEOGRAFIA E ESTATÍSTICA.IBGE cidades@Bahia Vitória da Conquista. Disponível em: <http://www.ibge.gov.br/cidadesat/painel/painel. php? codmun=293330\#>. Acesso em: 30 out. 2011. 
LEAL, S.M.C.; LOPES, M.J.M.; GASPAR, M.F.M. Representações sociais da violência contra a mulher na perspectiva da enfermagem. Interface: Comunicação, Saúde, Educação. Botucatu, v. 15, n. 37, p. 409-24, 2011.

LIMA, D.C.; BÜCHELE, F. Revisão crítica sobre o atendimento a homens autores de violência doméstica e familiar contra as mulheres. Physis: Revista de Saúde Coletiva. Rio de Janeiro, v. 21, n. 2, p. 721-43, 2011

LOBATO, G.L.; MORAES, C.L.; NASCIMENTO, M.C. Desafios da atenção à violência contra crianças e adolescentes no Programa de Saúde da Família em cidade de médio porte do Estado do Rio de Janeiro, Brasil. Cadernos de Saúde Pública. Rio de Janeiro, v. 28, n. 3, p. 1.749-58, 2012.

MINAYO, M.C.S. O desafio do conhecimento: pesquisa qualitativa em saúde. $12^{\text {a }}$ ed. São Paulo: Hucitec, 2010.

. A inclusão da violência na agenda da saúde: trajetória histórica. Ciência \& Saúde Coletiva, Rio de Janeiro, v. 11, supl. 1, p. 1.259-67, 2007.

MOREIRA, S.N.T. et al. Violência física contra a mulher na perspectiva de profissionais de saúde. Revista de Saúde Pública. São Paulo, v. 42, n. 6, p. 1.053-9, 2008.

OLIVEIRA, E.M. Fórum Violência Sexual e Saúde: Introdução. Cadernos de Saúde Pública, Rio de Janeiro, v. 23, n. 2, p. 455-8, 2007.

ONOCKO-CAMPOS, R.T. et al. Avaliação de estratégias inovadoras na organização da Atenção Primária à Saúde. Revista de Saúde Pública. São Paulo, v. 46, n. 1, p. 43-50, 2012.

ORGANIZAÇÃO MUNDIAL DA SAÚDE. Relatório Mundial sobre Violência e Saúde. Brasília: OMS/OPAS, 2002.

REICHENHEIM, M.E. et al. Violência e lesões no Brasil: efeitos, avanços alcançados e desafios futuros. Lancet, v. 5, p. 75-89, 2011.

SALIBA, O. et al. Responsabilidade do profissional de saúde sobre a notificação de casos de violência doméstica. Revista de Saúde Pública. São Paulo, v. 41, n. 3, p. 472-7, 2007.

SANTOS, I.M.V.; SANTOS, A.M. Acolhimento no Programa Saúde da Família: revisão das abordagens em periódicos brasileiros. Revista de Salud Publica. Bogotá, v. 13, n. 4, p. 703-16, 2011.

SANTOS, M.A.; VIEIRA, E.M. Recursos sociais para apoio às mulheres em situação de violência em Ribeirão Preto-SP, na perspectiva de informantes-chave. Interface: Comunicação, Saúde, Educação. Botucatu, v. 15, n. 36, p. 93-108, 2011.

SANTOS, F.P.A. et al. Estratégias de enfrentamento dos dilemas bioéticos gerados pela violência na escola. Physis: Revista de Saúde Coletiva. Rio de Janeiro, v. 21, n. 1, p. 267-81, 2011. 
SCHRAIBER, L.B.; D’OLIVEIRA, A.F.P.L.; COUTO, M.T. Violência e saúde: contribuições teóricas, metodológicas e éticas de estudos da violência contra mulher. Cadernos de Saúde Pública. Rio de Janeiro, v. 25, supl. 2, p. 205-16, 2012.

SERAPIONI, M.; SILVA, M.G.C. Avaliação da qualidade do Programa Saúde da Família em municípios do Ceará: uma abordagem multidimensional. Ciência \& Saúde Coletiva. Rio de Janeiro, v. 16, n. 11, p. 4.315-26, 2011.

WANDERBROOCKE, A.C.N.S.; MORÉ, C.L.O.O. Significados da violência familiar contra o idoso na perspectiva de profissionais da atenção primária à saúde. Ciência \& Saúde Coletiva. Rio de Janeiro, v. 17, n. 8, p. 2.095-103, 2012.

\section{Nota}

${ }^{1}$ R.T.S. Porto participou da concepção do estudo; coleta de dados; interpretação e análise dos resultados. J.P. Bispo Júnior participou da concepção do estudo; interpretação e análise dos resultados; redação do artigo e aprovação da versão final. E.C. de Lima participou da concepção do estudo; redação do artigo e aprovação da versão final. 
Domestic and sexual violence in the Family Health Strategy: professional performance and barriers to coping

Domestic and sexual violence is a complex issue and has multiple determinations. The problem requires awareness that goes beyond clinical and biological knowledge. This study aimed to analyze the perceptions of family health professionals on the fight against domestic and sexual violence. A qualitative research was conducted with 18 professionals of seven health teams in Vitoria da Conquista city, State of Bahia, Brazil. Thematic coding and categorizing was used for the analysis. The results showed two main categories: professional performance in the care of patients; barriers and difficulties in the fight against violence. Professionals showed difficulties in identifying cases in which care is based on the symptomatology approach. The main disclosed difficulties were fear and insecurity; work overload and inadequate training. Inter-sectorial articulation is needed for the fight against the problem and the development of permanent education policies.

Key words: domestic violence; sexual violence; primary health care; health professional; family health. 